\title{
Urban development of the territory using environmental organizational and technological solutions
}

\author{
Artem Subbotin ${ }^{1, *}$, Aleksandra Dostovalova ${ }^{1}$, and Vladislava Smirnova ${ }^{1}$ \\ ${ }^{1}$ Moscow State Construction University, 26 Yaroslavskoye Shosse, Moscow, 129337, Russia
}

\begin{abstract}
This article discusses issues aimed at determining the perception of modern urbanization. On the one hand, technological progress more and more enhances the environmental impact, thereby creating the prerequisites for the emergence of various environmental crises. On the other hand, it expands the possibilities of eliminating problems in this area. Therefore, there is a relationship between environmental impact, the level of economic development, and the level of development of civil society. Responsible attitude to the environment - an indicator of the high development of civilization - these are the aspects of the ecological development of megacities that urbanism deals with. Particular attention is paid to the need for an environmentally friendly modernization of modern urban spaces. The problem of reducing landscaped and forested areas in connection with the rapid increase in urban areas is considered. In order to clarify the latest urban development trends, innovative technologies and approaches to construction, as well as to the ecological organization of the urban environment, are considered.
\end{abstract}

\section{Introduction}

With the development of industry and the economy, urban growth invariably begins, which leads to a deterioration of the ecological situation and loss of ecosystem equilibrium. To date, a tendency toward population compaction has been identified. This is especially noticeable in the example of megacities, which, as a result of this process, are expanding and absorbing new less developed territories. Urban development brings with it an increase in human impact on the environment, therefore it is necessary to take care of the natural environment of cities. This kind of activity is engaged in such a new science for us as urban studies. Urban studies is a science that implies urban development, improving infrastructure and the quality of life of the population. She deals with such issues as the interaction of people with each other and the environment, transport routes and flows, the optimal organization of the best urban life for both the individual and society as a whole [1].

Progressive urbanization is an environment in which the natural environment, as part of the structure of the city, must not only be preserved, but also restored when developing new development strategies. In this case, the term PEC is used - a natural-ecological framework,

${ }^{*}$ Corresponding author: subbotin-art@mail.ru 
which describes an interconnected system of landscaped and natural areas adjacent to the city, performing functions to ensure a favorable environment. Based on studies of the impact of a high level of urbanization and natural conditions on the natural-ecological skeleton, a decrease in the area occupied by trees and shrubs by 8165 hectares within the PEC of Moscow was revealed [2]. It was concluded that in order to avoid degradation of $\mathrm{PEC}$ it is necessary to adhere to the principles of landscape urbanism and green building.

\section{Landscape urbanism}

Landscape urbanism, first of all, is aimed at creating an environmentally safe territory, as well as a socially-oriented space. The process of creating such an environment begins with the creation of city parks, embankments, squares, pedestrian streets, an interconnected system of transport spaces with landscaping, and ends with architectural objects, which are based on the principles of "green" architecture. And if we consider these objects from the perspective of landscape urbanism, they should form a single landscape-urban system of the city. By creating such an integrated system, we provide the basis for stabilizing the environmental situation in the city.

Since the degree of urban improvement is judged on national policy, the image of the city and the development of its infrastructure are indicators that identify problems of national importance. This approach is focused on the introduction of nature into the structure of the city by preserving its natural appearance, thus forming ecological and aesthetically attractive urban spaces.

\section{3 «Green building»}

"Green" building - the building and operation of buildings that have minimal environmental impact throughout the life of the operation and operation of such facilities. The basis of this construction is the idea of harmony between man and nature. Buildings should fit perfectly into the surrounding landscapes, and the shape of the buildings should correspond to the purpose and environmental conditions in which they are built [3].

During the construction of "green" facilities, the most important points are the environmental friendliness of materials, waste reduction, as well as reducing the level of consumption of energy and material resources (resource saving). Such materials may be wood, timberber - a mixture of sawdust and concrete, and ashkrit - an alternative to concrete, which uses fly ash (a byproduct of burning coal) instead of cement. For insulation of roofs and facades lamellar insulation can be used. Lamel is an innovative material, which is characterized by high rates of tensile strength to the front surface $-80 \mathrm{kPa}$, which is an important indicator when selecting material for the facade. When choosing materials for the construction of a green house, special attention must be paid to their energy consumption and less heat loss.

An important element of the thermal insulation of the building are the so-called "green" facades and roofs. "Green" facades are energy-saving, as they reduce heat loss through the building envelope, thereby reducing heat consumption. Also, these facades weaken the thermal regime of urban development, creating shading and evaporative cooling. For the device of "green" walls, climbing plants are used, which grow independently on the building envelope. The main components of such walls are the plants themselves, the substrate, supporting elements for the growth of plants and a system of pipes and pumps for fertilizer and watering. Usually shade-loving plants are planted in the lower part of the building, and plants that can tolerate high temperatures and wind are planted in the upper part. 


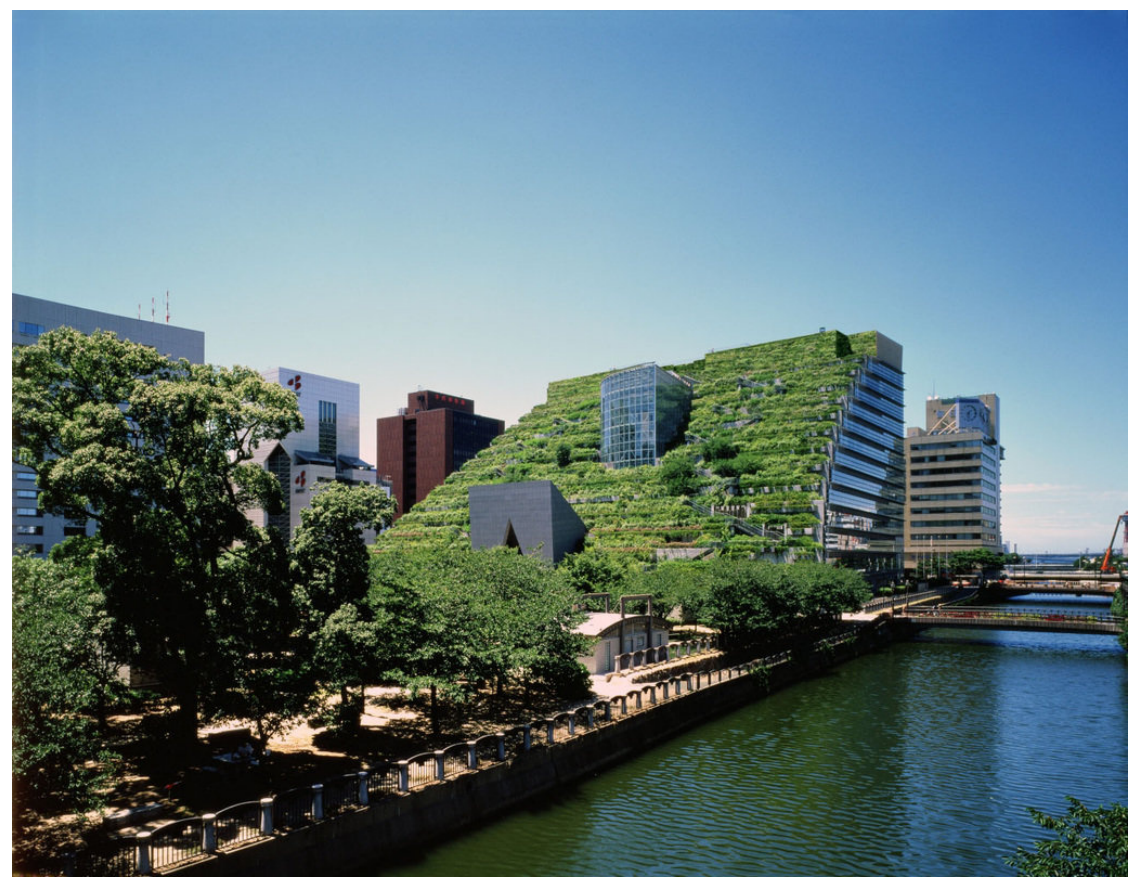

Fig. 1. Acros Tier Terraces (Fukuoka, Japan).

"Green" roofs are a multi-layer building envelope. The layers of this design are reinforced concrete slab, waterproofing carpet, thermal insulation from extruded polystyrene foam slabs, geotextile separation layer, drainage and filter layers, soil and plant layer.

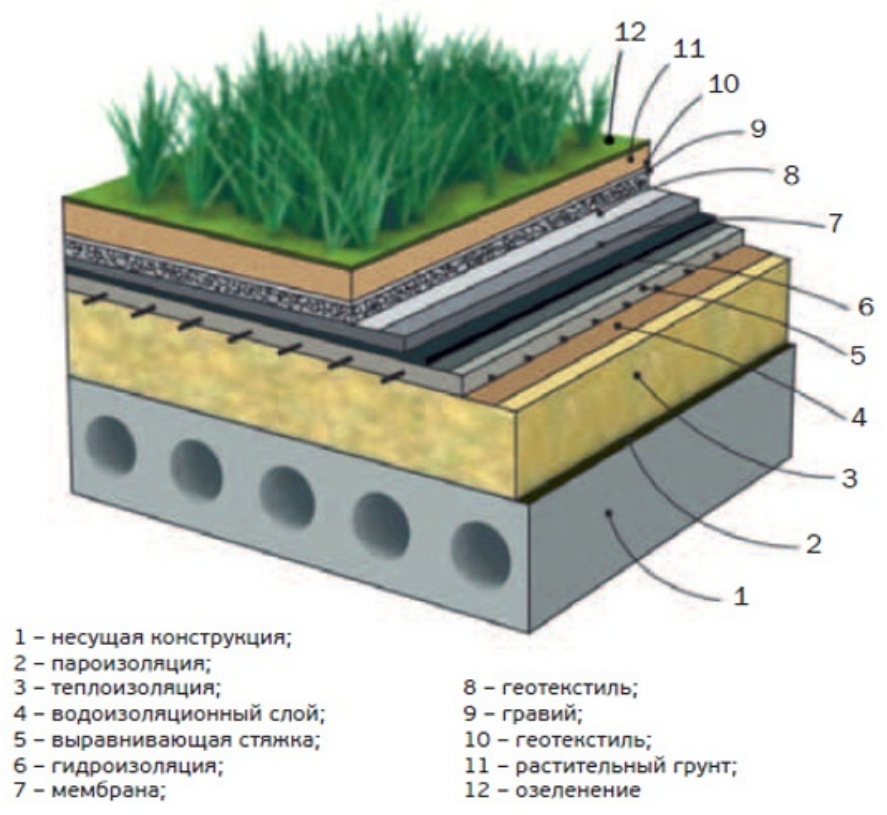


Fig. 2. Green Roof Construction.

The advantages of a green roof are the reduction of heating costs in the cold season due to the high resistance to heat transfer of the roof structure and the reduction of cooling costs in the warm season due to the natural evaporation of moisture; reduction of air pollution, i.e. enrichment with oxygen; improving the quality of acoustic comfort due to the absorption of urban noise by soil and plant layers; reduction in the amount of precipitation falling into the storm sewer [4]. The disadvantages of a green roof are the cost and complexity of the design, as well as the preservation of soil moisture for some plants, which can be a problem of protecting the building from moisture.

During the construction of such environmentally friendly houses and their use of renewable energy sources, as well as innovative technologies for arranging communications, which reduces energy consumption by $40 \%$ without loss of comfort.

An example of an efficient ventilation system is the Pegasos PRO Greenair HP decentralized ventilation system with an integrated heat pump. The uniqueness of the equipment lies in the optimal combination of two heat recovery cycles, thus solving two seemingly impossible tasks at once - to obtain tremendous energy efficiency with minimal energy consumption and excellent operation of the equipment without loss of high efficiency at low outdoor temperatures.

As for lighting, then it is possible to use the latest Solatube system. She catches the light through the roof dome and directs it down the light guide system. The optical fibers are adjusted between the rafters, they are easily installed without changing the design of the building. A light diffuser is installed on the ceiling, similar to a lamp that distributes light throughout a room. In the dark, the diffuser can be used to illuminate with artificial light.

Currently, "green" construction begins to develop at a tremendous pace, not only abroad, but also in our country. An example of a green building project in Russia is the Hypercube in Skolkovo. "Hypercube" is a building consisting of seven floors, the frame of which stands on concrete walls. The outer frame of this building allows you to change the facade structure. Solar panels are installed on the roof and upper floors, generating energy for the operation of electrical appliances. Also in the Hypercube are installed Parans system scavengers, which, turning after the sun, conduct sunlight through the optical fiber into the building. Water in the "Hypercub" comes from thirteen artesian wells, half of which is rainwater. For watering plants in the "green" building has its own system of purification and use of domestic wastewater. Heat pumps are used in the heating and cooling system, and heat losses are also reduced thanks to triple glazing and thermal curtains on the windows. Hypercube is controlled by Desigo Insight, which covers all its services, including heating, ventilation and air conditioning, lighting and even energy distribution. 


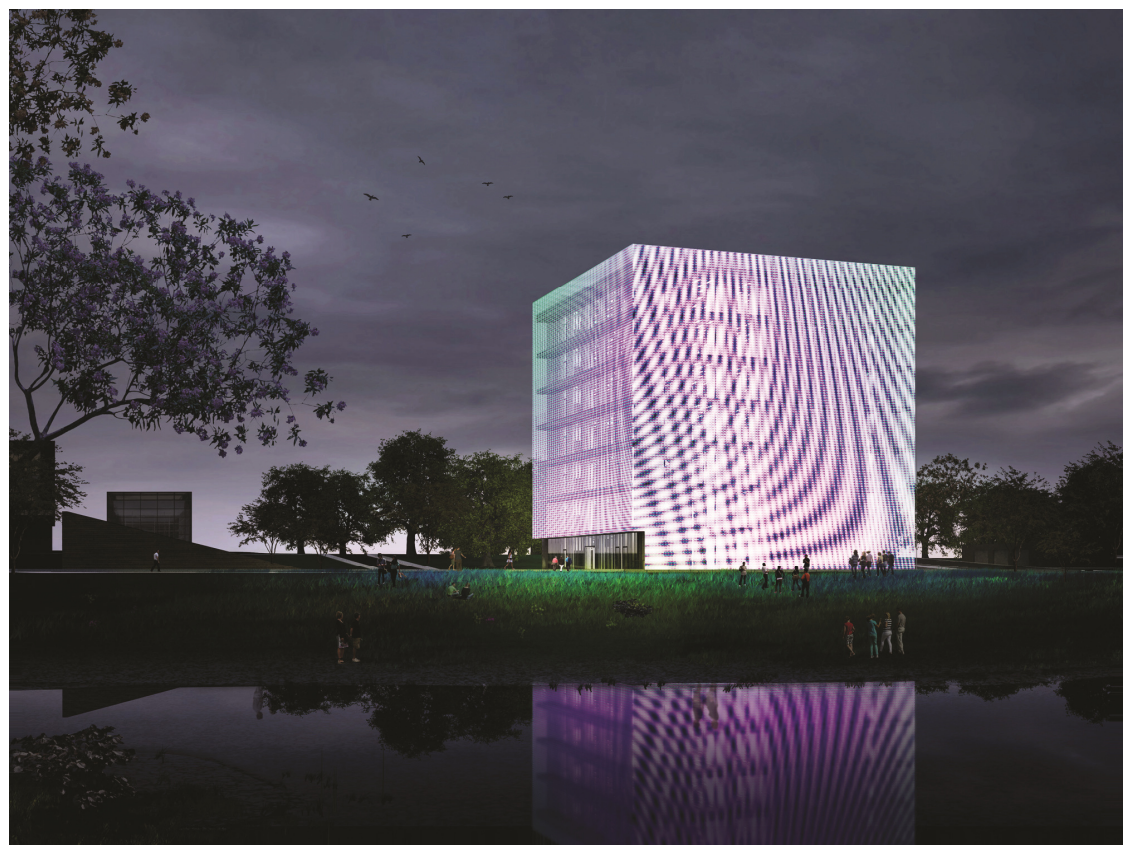

Fig. 3. «Hypercube» in Skolkovo.

\section{Urban transport}

Recently, in connection with the development of cities and population growth, the problem of the environmental impact of cars has become more acute. Therefore, the development of environmentally friendly and public transport has become an important aspect of urban studies. The modern infrastructure of road transport requires the creation of other additional systems that ensure the operability of environmental vehicles [5].

For example, take bicycle paths. Today, in Russia, a bicycle is not considered a safe and alternative means of transportation, as it is prescribed by the rules of the road to move along the curb, which exposes cyclists to additional dangers. It is also not forbidden to move along the sidewalks, but then there is a danger to pedestrians. That is why it is necessary to create a separate infrastructure for cyclists, which would be safe for all road users. The movement of cyclists is proposed to be allocated in a separate lane on the road, which, in turn, must be protected from other participants in the movement by barriers. So, in addition to marking, bike lanes have their own system of signs and notifications, and separation is due to curbs, posts, flowerbeds or even parking lots. Unfortunately, attempts to improve bicycle infrastructure are often not accepted by current motorists, as this will take part of the existing road.

Since today it is not possible to quickly switch to developed public transport and other environmental types of transportation, it is necessary to gradually upgrade the existing parking lots. There is a practice of creating "eco-parking". "Ecoparking" is a parking space created with the use of wire mesh made of concrete or polymer material in the base, sown with lawn grass [6]. Thus, when creating "green" parking lots, the percentage of landscaping in urban spaces increases. 


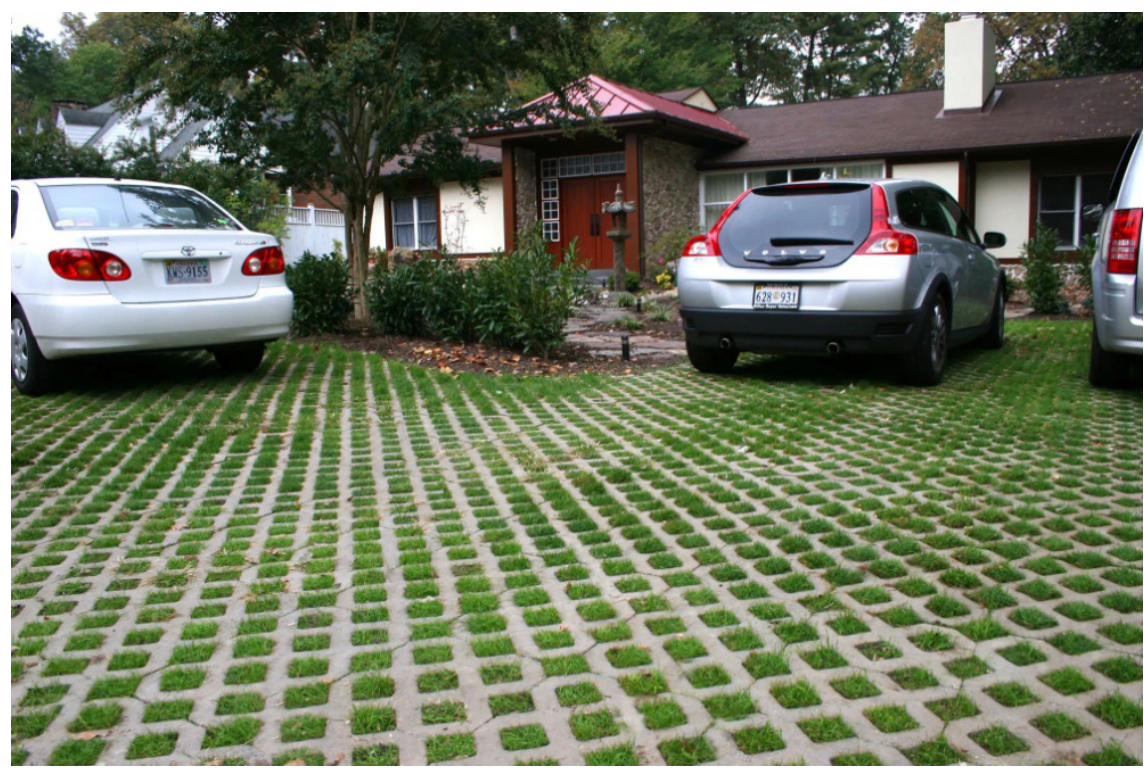

Fig. 4. «Ecoparking».

\section{Renovation of industrial facilities}

Also, at present, there is a tendency to increase the relevance of renovation of industrial zones. Renovation is a process aimed at the reconstruction, modernization or restoration of buildings without the complete destruction of structural integrity. This topic is especially important for large growing cities. Previously, industrial enterprises were located mainly outside the city, on its outskirts. But at the moment, the situation has changed somewhat, as modern cities are developing and occupying nearby territories. Thus, more and more industrial zones that ceased operations due to loss of efficiency are located within the city. If you do not develop such territories, the city will lose a lot of functional space and acquire neglected closed places.

There are several principles for the reconstruction of former industrial facilities:

1. The first principle is to use an existing building envelope. It is also possible to replace individual sections with other structural systems.

2. The second principle involves the creation of a different building envelope using new standards and requirements. This principle may be applicable, for example, in the construction of a new glass facade.

3. The third principle is similar to the second. Its main difference is that the new structural system is removable [7].

Successful examples of renovation of former industrial facilities in Moscow are the Center for Contemporary Art "Vinzavod " and the Design factory "Flacon". Both of these objects were reconstructed according to the first principle, that is, they used the already existing building envelope. Now, the former abandoned territories have become new cultural places with accessible spaces and convenient infrastructure. 


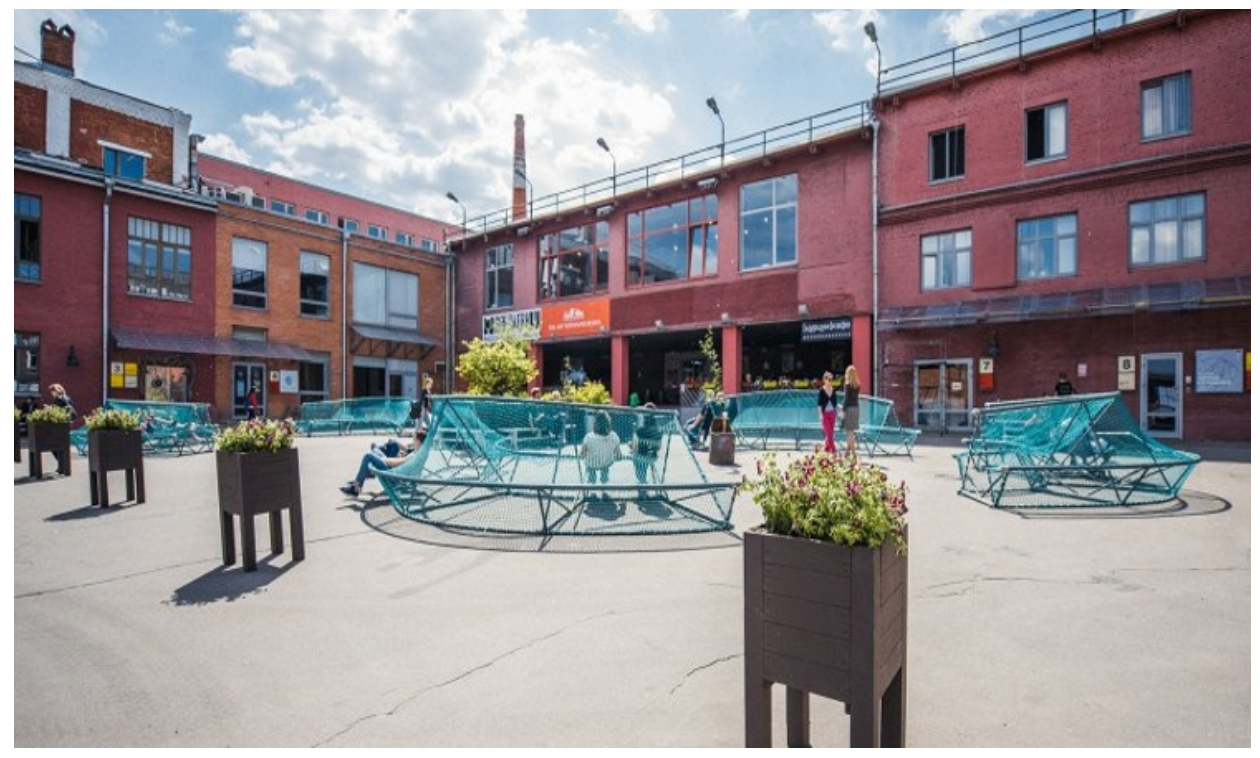

Fig. 5. Center for Contemporary Art " Vinzavod ".

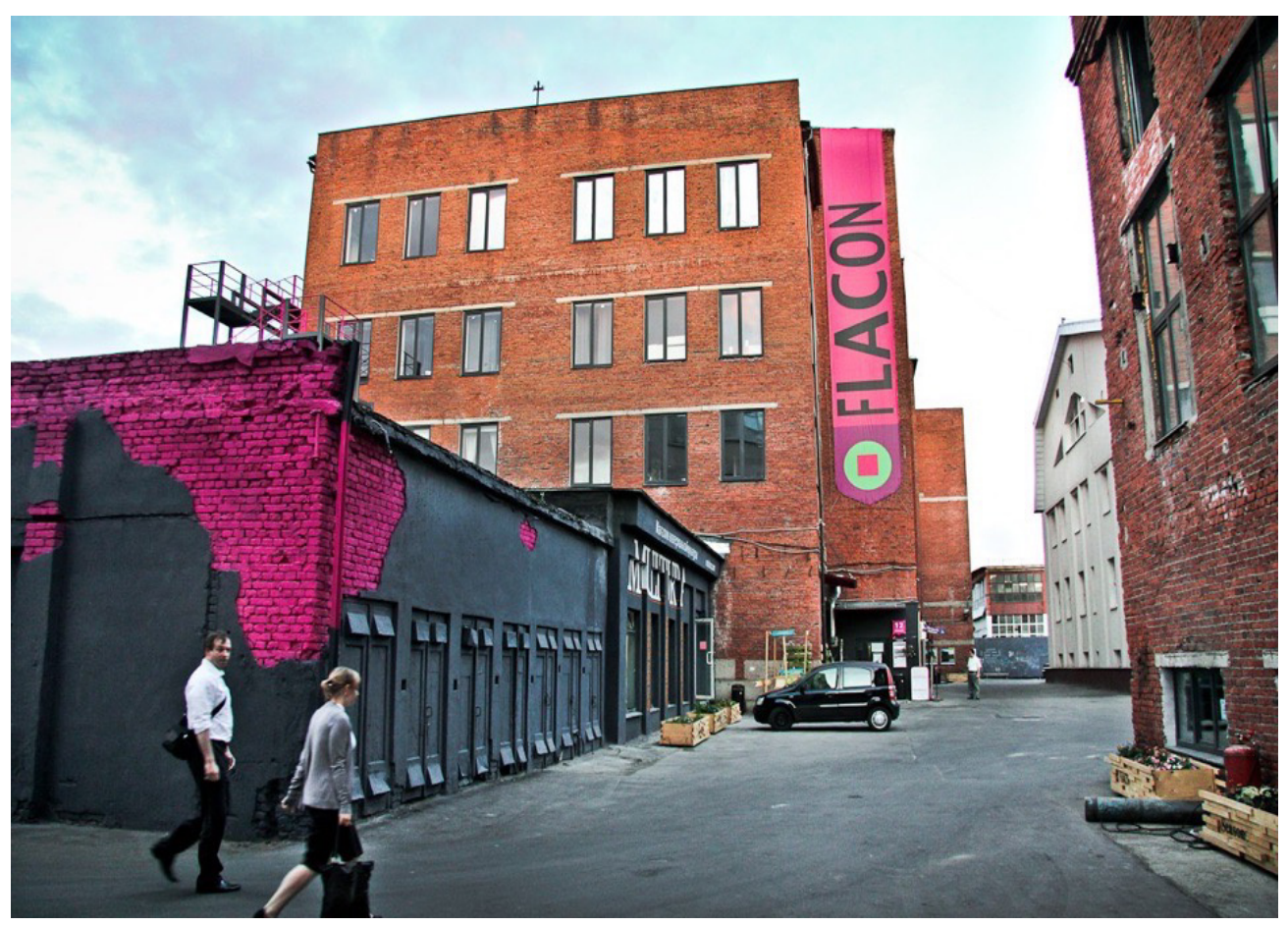

Fig. 6. Design factory "Flacon".

\section{Conclusion}

In this way, we can conclude that the problems of modern urbanization, related to the city and the environment, are becoming increasingly relevant, since most of the population lives 
in cities. Preserving and maintaining the environment in an acceptable state is one of the most important topics today. Therefore, it is necessary to use building materials that do not have a harmful effect on humans and the urban ecosystem. It is also necessary to create and apply new approaches to the regulation and development of urban gardening development plans. Urban landscaping indicators today are indicators of sustainable urbanization.

\section{References}

1. A.A. Barabanov, Urbanistika segodnya, Akademicheskiy vestnik UralNIIproyekt RAASN (2009)

2. V.M. Yablokov, Geoinformatsionnyy analiz struktury $i$ dinamiki prirodnoekologicheskogo karkasa. Moskvy na osnove otkrytykh geodannykh, Vestnik Moskovskogo universiteta. Seriya 5. Geografiya (2018)

3. N.A. Yesin, T.I. Tulyakova, A.A. Istomin, Zelenoye stroitel'stvo, Eur. Sci. (2017)

4. ZH.I. Sadykhova, «Zelenoye» stroitel'stvo v Rossii $i$ mire. Trudy mezhdunarodnogo simpoziuma «Nadezhnost' i kachestvo» (2018)

5. A. Subbotin, S. Grigoryan, "Road service facilities for improving the ecological state using the PPP mechanism". Top. Prob. of Arch., Civil Eng. and Envir.l Ec., TPACEE (2018)

6. A.S. Subbotin, L.A. Prostotina, "Stroitel'stvo ob"yektov dorozhnogo servisa $v$ usloviyakh parkov i zapovednikov" (Zhurnal «Transportnoye stroitel'stvo» №2 (2019)

7. A.G. Pestrikova, Ye.A. Burda, Vliyaniye ob ob"yektakh promyshlennogo naznacheniya na arkhitekturno-prostranstvennuyu kompozitsiyu krupnykh gorodov. Vísnik Pridíprovs'kíy gosudarstvennoy derzhavy akademii bud' ta arkhitektorov (2013) 